\title{
The Danish Sarcoma Database
}

This article was published in the following Dove Press journal:

Clinical Epidemiology

25 October 2016

Number of times this article has been viewed

Peter Holmberg Jørgensen'

Gunnar Schwarz Lausten ${ }^{2}$

Alma B Pedersen ${ }^{3}$

'Tumor Section, Department of Orthopedic Surgery, Aarhus University Hospital, Aarhus, ${ }^{2}$ Tumor Section, Department of Orthopedic Surgery, Rigshospitalet, Copenhagen, ${ }^{3}$ Department of Clinical Epidemiology, Aarhus University Hospital, Aarhus, Denmark

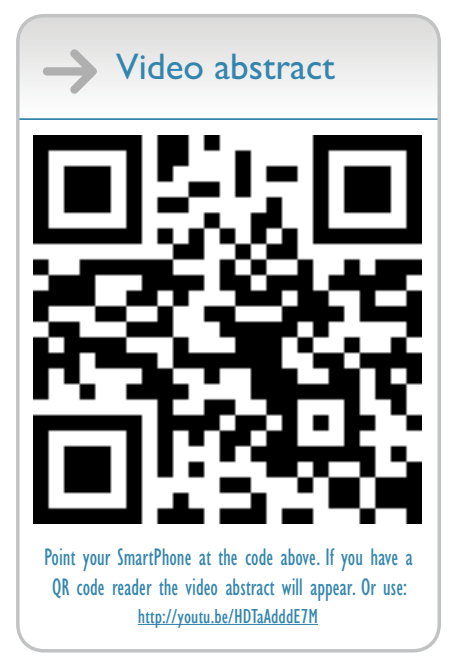

Correspondence: Peter Holmberg Jørgensen

Tumor Section, Department of Orthopedic Surgery, Aarhus University Hospital, Nørrebrogade 44, 8000 Aarhus C, Denmark

Tel +45 78462784

Fax +45 78464120

Email petejoer@rm.dk
Aim: The aim of the database is to gather information about sarcomas treated in Denmark in order to continuously monitor and improve the quality of sarcoma treatment in a local, a national, and an international perspective.

Study population: Patients in Denmark diagnosed with a sarcoma, both skeletal and ekstraskeletal, are to be registered since 2009.

Main variables: The database contains information about appearance of symptoms; date of receiving referral to a sarcoma center; date of first visit; whether surgery has been performed elsewhere before referral, diagnosis, and treatment; tumor characteristics such as location, size, malignancy grade, and growth pattern; details on treatment (kind of surgery, amount of radiation therapy, type and duration of chemotherapy); complications of treatment; local recurrence and metastases; and comorbidity. In addition, several quality indicators are registered in order to measure the quality of care provided by the hospitals and make comparisons between hospitals and with international standards.

Descriptive data: Demographic patient-specific data such as age, sex, region of living, comorbidity, World Health Organization's International Classification of Diseases - tenth edition codes and TNM Classification of Malignant Tumours, and date of death (after yearly coupling to the Danish Civil Registration System). Data quality and completeness are currently secured.

Conclusion: The Danish Sarcoma Database is population based and includes sarcomas occurring in Denmark since 2009. It is a valuable tool for monitoring sarcoma incidence and quality of treatment and its improvement, postoperative complications, and recurrence within 5 years follow-up. The database is also a valuable research tool to study the impact of technical and medical interventions on prognosis of sarcoma patients.

Keywords: sarcoma, skeletal and ekstraskeletal, population-based database, online database, quality indicators

\section{Aim}

The Danish Sarcoma Group is one of the Danish multidisciplinary cancer groups (DMCG) fulfilling different criteria to be part of the parachute organization DMCG.dk. One criterion is to have a database approved by the Danish National Board of Health. Danish Sarcoma Database (DSD) was established as a national, population-based database on January 1, 2009. The aim of the database is to gather information about incidence, treatment, and prognosis of sarcomas (including borderline malignant connective tissue tumors) in Denmark in order to monitor and improve the quality of sarcoma treatment in both a national and an international perspective. 


\section{Study population}

Sarcoma is a rather seldom malignant tumor entity (incidence approximately six to eight per 100,000 inhabitants corresponding to $\sim 350$ new cases/year), ${ }^{1}$ and according to the Danish National Board of Health, all sarcoma treatment in Denmark must be confined to two nationally approved sarcoma centers at Aarhus University Hospital, Aarhus, and Rigshospitalet/Herlev Hospital, Copenhagen. The database has since its establishment included all bone and soft tissue sarcomas of the musculoskeletal system in Denmark, including the trunk wall. Together, these locations comprise $\sim 80 \%$ of all sarcomas. Also, the treatment of intra-abdominal and retroperitoneal sarcomas and sarcomas of the neck and face has been centralized at Copenhagen and Aarhus so that almost all sarcomas in Denmark are now registered in DSD (Figure 1). According to Figure 1, there seems to be an increase in the number of patients at least from 2013 to 2014. This is not due to increased inclusion of patients from previously unregistered anatomical region, and also, the distribution between superficial and deep-seated tumors is unchanged. We do not know for sure whether the increase reflects an increased amount of sarcomas, but the figures for 2015 (not yet validated) indicate that the increase is only transitory.

Sarcomas of the female genitalia have traditionally been registered in the Danish Gynaecological Cancer Database only, and not consequently in DSD. Therefore, a new corporation between the two databases has been established, and from 2015, the gynecological sarcomas ( $40 /$ year) will be registered in DSD too. The database is approved by the Danish National Board of Health as a clinical quality database and economically supported by the Danish health authorities. As a consequence, all clinicians treating sarcomas are obliged to report to the database. In addition, registration to DSD can take place without consent due to a law regulation from 2006 on the reporting of information to clinical databases adopted by the Ministry of Health. So far, this is our best guarantee for a high completeness of the database.

As all citizens in Denmark are provided with a unique ten-digit civil registration code describing age, sex, and date of birth, it is possible to link DSD to different administrative databases, eg, the Danish National Pathology Registry. In this registry, all histological specimens from all sarcomas are registered according to the World Health Organization classification. ${ }^{2}$ We have cross-checked the registry for 2013 and 2014 and have established an ongoing validation project to clarify whether it can be used for a precise assessment of the completeness of the database.

By December 31, 2014, 2,000 patients were registered in the database: $49 \%$ women and $51 \%$ men, with a mean age ranging from 53.9 to 56.2 years (Table 1) and an age distribution from 2 months to 95 years (Figure 2).

\section{Main variables}

The database contains information of sarcomas and borderline tumors, including giant cell tumor of the bone and aggressive fibromatosis (Figure 3), and contains information about the patients before and after their first visit in a sarcoma center. Thus, $23 \%$ of the patients have had a resection and $16 \%$ a biopsy before referral to the sarcoma center involving both superficial and deep-seated tumors.

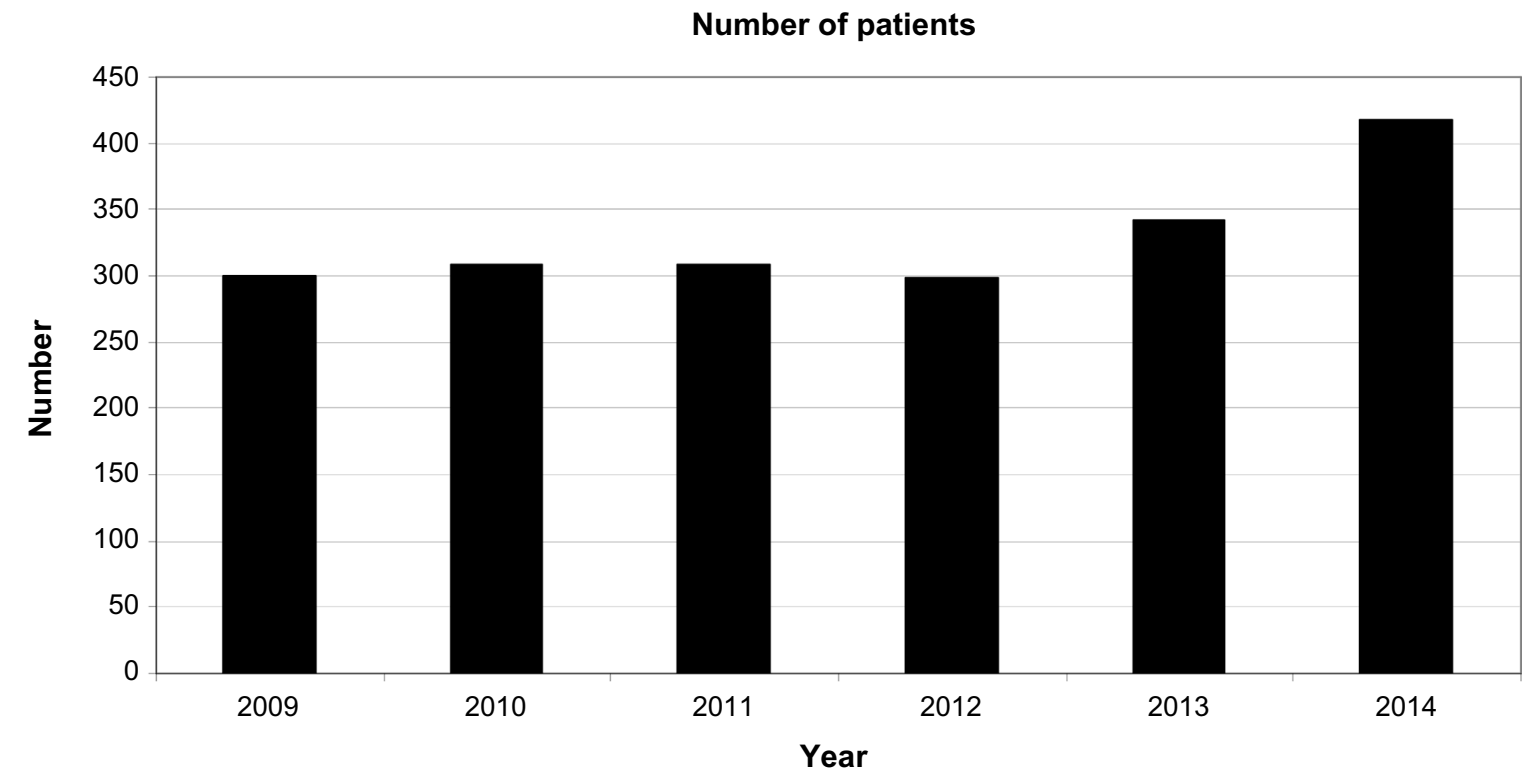

Figure I The amount of patients registered in the Danish Sarcoma Database every year since the start of the database.

Note: The increase in the amount of patients from the first 5 years to 2014 is mainly due to a more complete registration of extraskeletal sarcomas. 
Table I The mean age for each year included in the sarcoma database

\begin{tabular}{llllll}
\hline Year & $\begin{array}{l}\text { Number of } \\
\text { patients }\end{array}$ & $\begin{array}{l}\text { Age } \\
\text { (mean, } \\
\text { years) }\end{array}$ & $\begin{array}{l}\text { Lower } \\
\text { quartile }\end{array}$ & $\begin{array}{l}\text { Upper } \\
\text { quartile }\end{array}$ & $\begin{array}{l}\text { Quartile } \\
\text { range }\end{array}$ \\
\hline 2009 & 298 & 54.0 & 39.3 & 68.0 & 28.7 \\
2010 & 309 & 53.9 & 40.2 & 68.4 & 28.3 \\
2011 & 305 & 56.3 & 44.5 & 69.7 & 25.2 \\
2012 & 294 & 54.3 & 43.7 & 68.3 & 24.5 \\
2013 & 342 & 55.8 & 43.7 & 69.9 & 26.2 \\
2014 & 412 & 56.2 & 43.6 & 70.9 & 27.4 \\
\hline
\end{tabular}

Most of the variables (the main variables are described in Table 2) in the database can be applied to any patient, but sarcomas occur in any part of the body and therefore some variables may not be meaningful in every case. For example, the margin of resection of a tumor in an extremity can be described as intralesional, marginal, wide, or radical, but the distinctions between marginal and wide cannot be made for a retroperitoneal tumor.

When all diagnostic procedures have been performed, it is decided whether the treatment is intended to be curative or palliative, a decision made at the weekly multidisciplinary tumor conferences based on the results of the investigations of the patient's tumor. In all, $14 \%$ of the patients have disseminated disease at referral to a degree that curative treatment is not considered possible.

\section{Comorbidity}

Comorbidity is registered according to the Charlson comorbidity score. ${ }^{3}$ Information about comorbidity is gathered at the patient's first visit at the sarcoma center. The information can (with patient's consent) be supplied by electronic access to the patient's previous medical records.

\section{Diagnoses}

The sarcoma patients are registered using the International Classification of Diseases - Tenth edition (ICD-10) codes and the tumor-node-metastasis (TNM) Classification of Malignant Tumours. Unfortunately, the ICD-10 codes are not fully descriptive for sarcomas as in some organs; for example, in the breast, a sarcoma can only be classified as a breast cancer and not as a breast sarcoma (malignant connective tissue tumor). Therefore, the database cannot be completely validated by cross-checking with the Danish Cancer Registry.

\section{Treatment}

All types of treatment given to the patients are registered (surgery, radiation and chemotherapy for both primary tumor and possible recurrence), and both early and late complications are registered.

\section{Pathology}

The sarcomas in the database are graded according to the Fédération Nationale des Centres de Lutte Contre le Cancer (FNCLCC) system ${ }^{4}$ (if gradable).

For many years, it has been a debate which surgical margin is the optimal to reduce the risk of recurrence. To help answering this question, the pathologist, for the soft tissue tumors of the musculoskeletal system, measures the smallest distance from

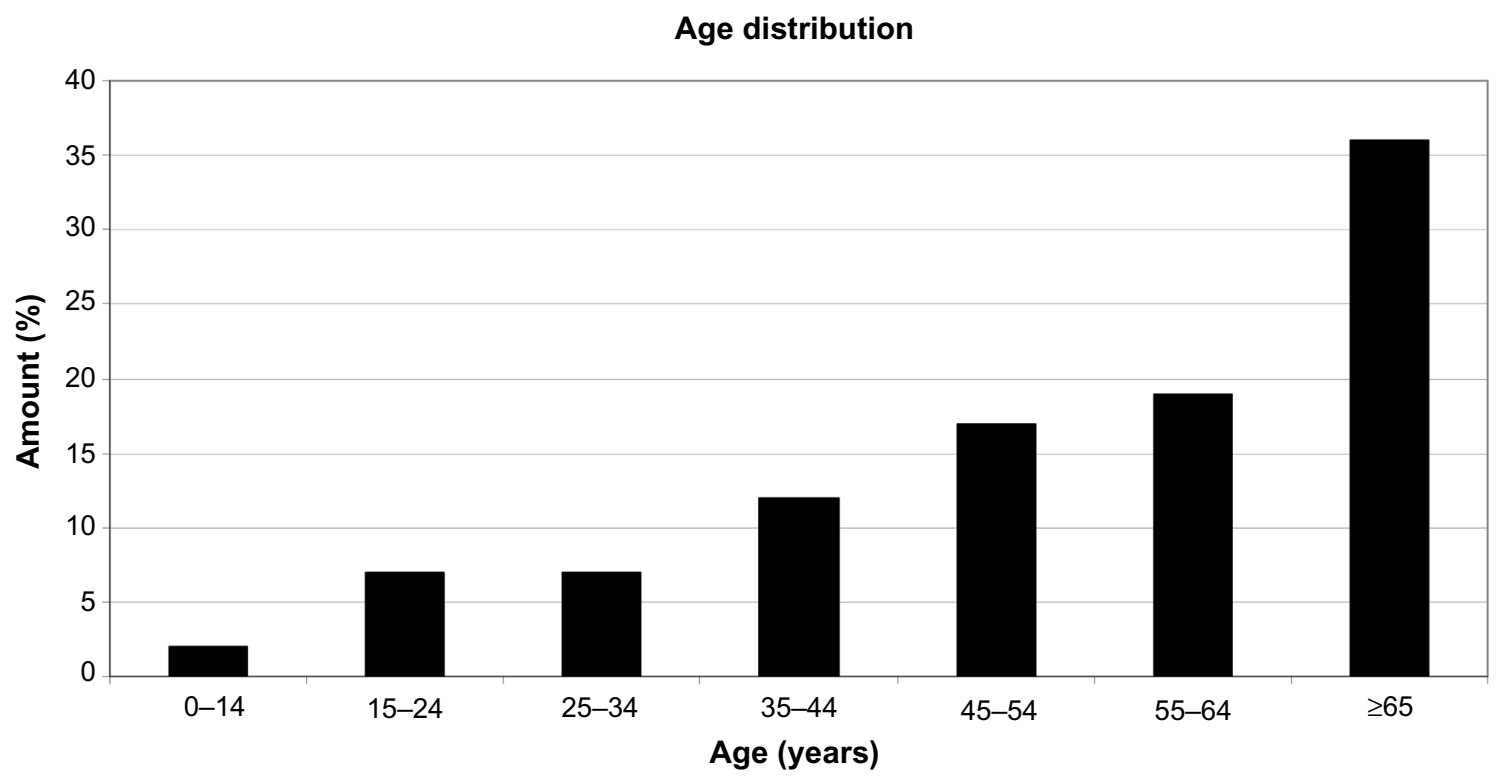

Figure 2 The relative distribution of patients related to age. 


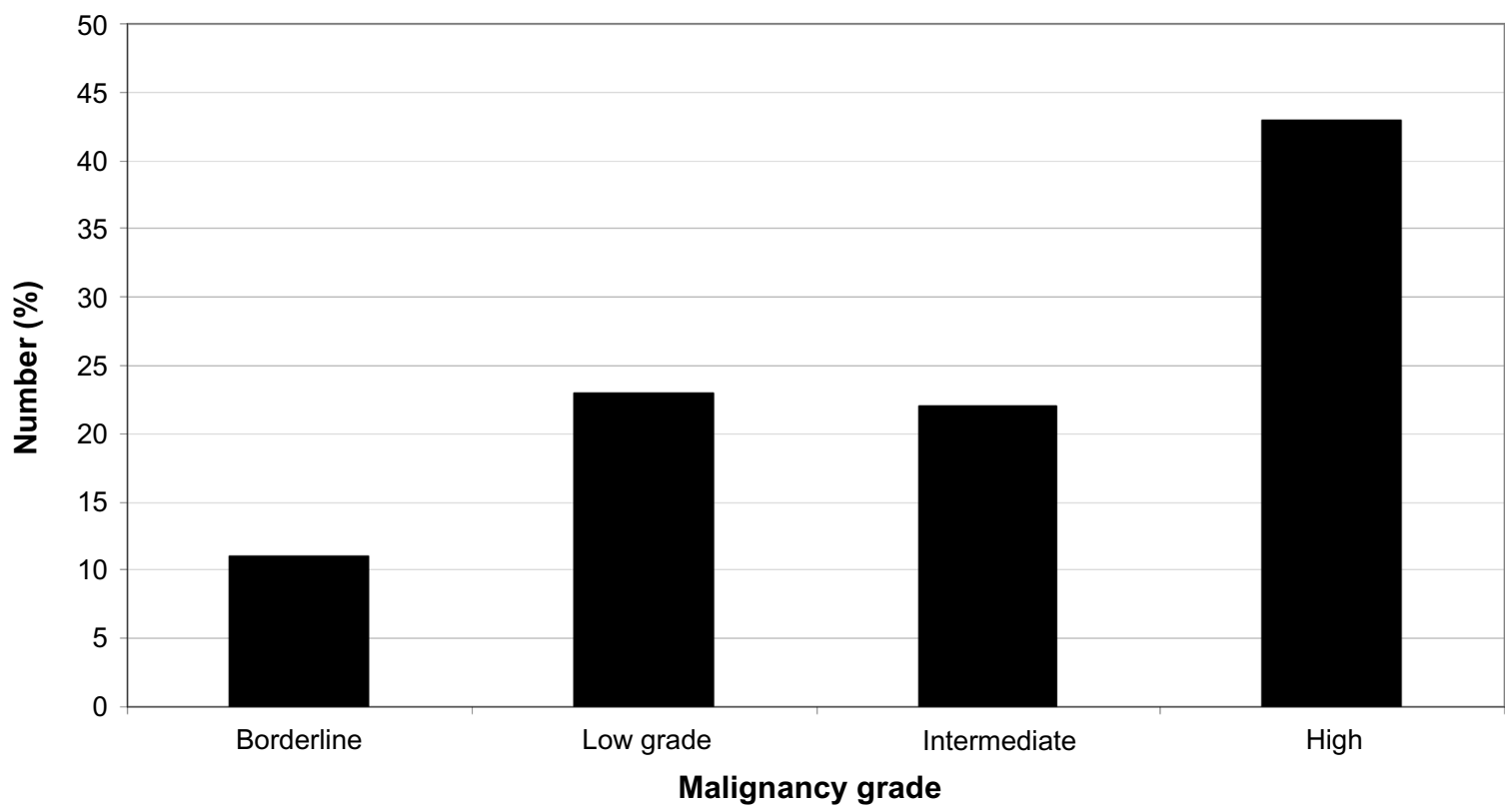

Figure 3 The distribution of malignancy grade among sarcomas registered in the Danish Sarcoma Database.

tumor to a well-defined margin, eg, a fascia, and to an undefined margin as the resection line of a muscle containing the tumor.

\section{Mortality}

The DSD is regularly linked to the Danish Civil Registration System. This registry has recorded all changes in vital status and migration for the entire Danish population since 1968 (thus including all sarcoma patients registered in DSD), with daily electronic updates.

\section{Data quality}

The database is constructed to secure a good data quality through a current online registration by the clinician responsible for a given event, eg, surgery. However, some data will be missing and some data have been typed erroneously. For this reason, in both of the two sarcoma centers, a dedicated person has been employed to cross-check all data with the patients' medical records when the patient has finished treatment and changed to follow up. Data validity is further secured by some build-in logical locks that prevent the sequence of events from being not chronological, for example, if date of operation erroneously is registered as before onset of symptoms.

\section{Quality indicators}

DSD is a combined quality and research database, and therefore, some quality indicators have been defined (Table 3 ).

For indicators 7 and 8, we still only have the figures for the first year of the database (2009), being $19 \%$ and $16 \%$ on the national level, respectively.
If the standards are not fulfilled, the relevant center is asked to perform medical record audit in order to find an explanation and suggest a plan for future improvement, if possible. For example, in those cases where radiotherapy has not been initiated within 60 days after surgery, this has been due to patient-related causes, such as wound problems, other disease, or the like.

\section{Follow-up}

All patients are offered a follow-up program from 3 to 6 months to 5 years to 10 years after the end of treatment, depending on the type of tumor. At the first follow-up (3-6 months), after 1 year, and at the last follow-up, a Musculoskeletal Tumor Society score ${ }^{5}$ for patients treated for an extremity tumor is calculated.

\section{Examples of research}

So far, publications based on the DSD included clinical results of inverse shoulder prosthesis after tumor resection, ${ }^{6}$ alarm symptoms of soft tissue and bone sarcomas, ${ }^{7}$ some effects of cancer patient pathways, ${ }^{8}$ a Danish validation of the TESS-score, ${ }^{9}$ and a characterization of tumor type in patients referred after unplanned excision of tumor outside a sarcoma center. ${ }^{10}$

At present, three $\mathrm{PhD}$ studies based on the $\mathrm{DSD}$ are taking place, with the titles:

- Comorbidity, socioeconomic position, use of health care services and causes of death in sarcoma patients: four nationwide population based studies;

- The impact of cancer pathways on the improvement of diagnostics in soft tissue and bone sarcomas; and 
Table 2 Variables of the sarcoma database

\begin{tabular}{|c|c|}
\hline Variable & Description \\
\hline asic data & $\begin{array}{l}\text { Age, sex } \\
\text { Dates: I. first symptoms, 2. referral, 3. treatment of } \\
\text { tumor before referral, } 4 \text {. first visit at sarcoma center } \\
\text { Intention of treatment: curative or palliative } \\
\text { ICD-I0 codes, TNM classification }\end{array}$ \\
\hline Comorbidity & Charlson comorbidity score \\
\hline $\begin{array}{l}\text { Imaging } \\
\text { procedures }\end{array}$ & $\begin{array}{l}\text { Tumor and other locations: X-ray, MRI, CT, } \\
\text { ultrasound, PET-CT, bone scan, and others }\end{array}$ \\
\hline $\begin{array}{l}\text { Tumor } \\
\text { characteristics }\end{array}$ & $\begin{array}{l}\text { Size } \\
\text { Localization: anatomical } \\
\text { Soft tissue: subcutaneous, deep seated } \\
\text { Bone: for long bones (diaphysis, metaphysis, } \\
\text { epiphysis) } \\
\text { Extension: intraosseous, cortical, extraosseous } \\
\text { Metastasis: local, distant }\end{array}$ \\
\hline $\begin{array}{l}\text { Primary } \\
\text { surgery }\end{array}$ & $\begin{array}{l}\text { Date } \\
\text { Type of surgery: local resection, amputation } \\
\text { Supplementary procedures: prosthesis, tissue } \\
\text { grafting, flap surgery, rotational plastic, cement, } \\
\text { bone substitute, bone bridging, bone transport, } \\
\text { arthrodesis, prosthetic mesh repair. } \\
\text { Surgical margin (surgeon's evaluation): radical, } \\
\text { intralesional (with or without macroscopical } \\
\text { contamination of tissue outside tumor) }\end{array}$ \\
\hline $\begin{array}{l}\text { Oncological } \\
\text { treatment }\end{array}$ & $\begin{array}{l}\text { Date } \\
\text { Radiation therapy (type, dose, number of fractions), } \\
\text { chemotherapy (type, duration, ILP) }\end{array}$ \\
\hline Recurrence & $\begin{array}{l}\text { Date } \\
\text { Local, metastasis } \\
\text { Type of treatment }\end{array}$ \\
\hline Pathology & $\begin{array}{l}\text { Histopathological diagnosis including WHO M-code } \\
\text { Grade of malignancy (FNCLCC system) } \\
\text { Surgical margin (pathologist's evaluation) } \\
\text { Smallest distance from tumor to resection surface } \\
\text { Growth pattern } \\
\text { Vascular ingrowth } \\
\text { Necrosis after chemotherapy }\end{array}$ \\
\hline Complications & $\begin{array}{l}\text { Postoperatively: early ( }<\text { I month postoperatively), late } \\
\text { Post radiation } \\
\text { Post chemotherapy }\end{array}$ \\
\hline Follow-up & $\begin{array}{l}\text { Date for every follow-up } \\
\text { MSTS score ( } 3 \text { months, I year, } 5 \text { years) }\end{array}$ \\
\hline Death & $\begin{array}{l}\text { Date } \\
\text { Reason (tumor, complication of treatment, others) }\end{array}$ \\
\hline
\end{tabular}

Abbreviations: ICD, International Classification of Diseases; TNM, tumor-nodemetastasis; MRI, magnetic resonance imaging; CT, computed tomography; PET, positron emission tomography; ILP, isolated limb perfusion; WHO, World Health Organization; MSTS, Musculoskeletal Tumor Society; FNCLCC, Fédération Nationale des Centres de Lutte Contre le Cancer.

- Improvement in physical rehabilitation in sarcoma patients - a national multicenter study.

Other ongoing studies including patients from the database are:

- Comparison of clinical results with bone allograft or PMMA after curettage for giant cell tumor of the bone;
Table 3 Quality indicators with standards

\begin{tabular}{ll}
\hline Indicator & Standard \\
\hline I. Proportion of patients with subfascial tumor where & $>95 \%$ \\
MRI or CT of tumor has been performed & \\
2. Proportion of patients with intermediate or high-grade & $>95 \%$ \\
malignancy where chest CT or PET-CT has been & \\
performed & \\
3. Proportion of patients with intermediate or high-grade & $>95 \%$ \\
malignancy bone tumor where bone scan or PET-CT has & \\
been performed & \\
4. Proportion of patients operated with insufficient surgical & $<10 \%$ \\
margin at primary surgery & \\
5. Proportion of patients admitted to postoperative radiation & $>80 \%$ \\
therapy who start therapy within 60 days after surgery & \\
6. Proportion of patients seen at the first clinical follow-up & $>90 \%$ \\
within 6 months after the end of treatment & \\
7. Proportion of patients having a local recurrence within & $<20 \%$ \\
5 years after the end of treatment & \\
8. Proportion of patients having a metastasis within 5 years & $<30 \%$
\end{tabular}

Abbreviations: MRI, magnetic resonance imaging; CT, computed tomography; $\mathrm{PET}$, positron emission tomography.

- Radiation induced angiosarcoma of the breast; and

- Thoracic wall resection due to sarcoma.

\section{Administrative issues and funding}

DSD is economically supported solely by the Danish National Health Authorities as part of the DMCG.dk program. Also, as part of this program, the Department of Clinical Epidemiology, Centre for Clinical Epidemiology and Biostatistics, North, Aarhus University Hospital is a mandatory cooperative institution with the aim of delivering epidemiological and biostatistical assistance.

Physicians employed at departments who are members of the Danish Sarcoma Group have access to the database. Access to data for research must be given by both the steering group of the database and the Danish Clinical Registry, which is a national parachute organization approving the databases for funding.

\section{Conclusion}

The DSD is a national population-based database now including all sarcomas in Denmark, both the musculoskeletal and the extraskeletal tumors (including borderline malignant tumors), which makes it a rather unique database in comparison with other countries. DSD provides possibilities to data linkage and cooperation for quality and research studies with other sarcoma groups.

\section{Acknowledgment}

This article was funded by the Program for Clinical Research Infrastructure established by the Lundbeck Foundation 
and the Novo Nordisk Foundation and administered by the Danish Regions.

\section{Disclosure}

The authors report no conflicts of interest in this work.

\section{References}

1. Jørgensen PH, Lausten GS, Pedersen AB [webpage on the Internet]. Dansk Sarkom Database (DSD). Available from: https://www.sundhed. dk/content/cms/94/38494_årsrapport-sarkom-2014_final-.pdf. Accessed August 31, 2015.

2. Fletcher CDM, Bridge JA, Hogendoorn PCW, Mertens F, editors. World Health Organisation Classification of Tumours: Tumours of Soft Tissue and Bone. 4th ed. Geneva: WHO Press; 2012.

3. Charlson ME. A new method of classifying prognostic comorbidity in longitudinal studies: development and validation. J Chronic Dis. 1987;40:373-383.

4. Coindre J-M. Grading of soft tissue sarcomas. Arch Pathol Lab Med. 2006;130:1448-1453.
5. Enneking WF, Dunham W, Gebhardt MC, Malawer M, Pritchard DJ. A system for the functional evaluation of reconstructive procedures after surgical treatment of tumors of the musculoskeletal system. Clin Orthop Relat Res. 1993;286:241-246.

6. Kaa A, Jørgensen PH, Johansen HV, Søjbjerg JO. Reverse shoulder prosthesis after resection due to tumour. Bone Joint J. 2013;95-B: 1551-1555.

7. Dyrop HB, Vedsted P, Safwat A, et al. Alarm symptoms of soft tissue and bone sarcoma among patients referred to a specialist center. Acta Orthop. 2014;85(6):657-662.

8. Dyrop HP, Safwat A, Vedsted P, et al. Cancer patient pathways shortens waiting times and accelerates the diagnostic process of suspected sarcoma patients in Denmark. Health Policy. 2013;113(1-2):110-117.

9. Sæbye C, Safwat A, Kaa AK, Pedersen NA, Keller J. Validation of a Danish version of the Toronto extremity salvage score questionnaire for patients with sarcoma in the extremities. Dan Med J. 2014;61(1):A4734.

10. Dyrop HB, Safwat A, Vedsted P, et al. Characteristics of 64 sarcoma patients referred to a sarcoma center after unplanned excision. J Surg Oncol. 2016;113(2):235-239.
Clinical Epidemiology

\section{Publish your work in this journal}

Clinical Epidemiology is an international, peer-reviewed, open access, online journal focusing on disease and drug epidemiology, identification of risk factors and screening procedures to develop optimal preventative initiatives and programs. Specific topics include: diagnosis, prognosis, treatment, screening, prevention, risk factor modification,

Submit your manuscript here: http://www.dovepress.com/clinical-epidemiology-journal

\section{Dovepress}

systematic reviews, risk \& safety of medical interventions, epidemiology \& biostatistical methods, and evaluation of guidelines, translational medicine, health policies \& economic evaluations. The manuscript management system is completely online and includes a very quick and fair peer-review system, which is all easy to use. 